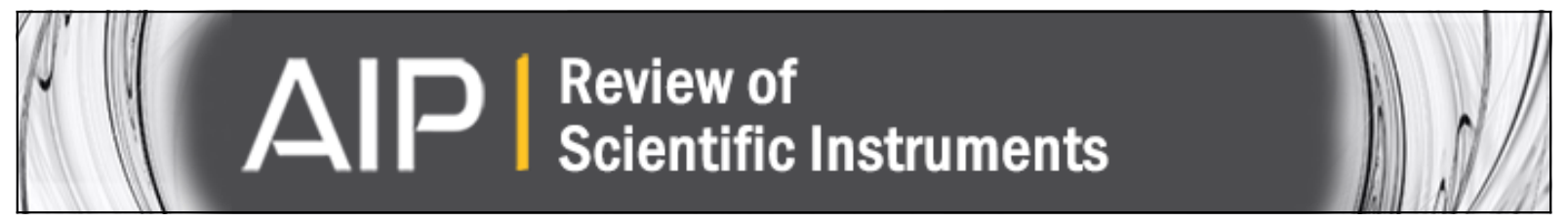

\title{
Performance of the Los Alamos National Laboratory spallation-driven solid-deuterium ultra-cold neutron source
}

A. Saunders, M. Makela, Y. Bagdasarova, H. O. Back, J. Boissevain, L. J. Broussard, T. J. Bowles, R. Carr, S. A. Currie, B. Filippone, A. García, P. Geltenbort, K. P. Hickerson, R. E. Hill, J. Hoagland, S. Hoedl, A. T. Holley, G. Hogan, T. M. Ito, Steve Lamoreaux, Chen-Yu Liu, J. Liu, R. R. Mammei, J. Martin, D. Melconian, M. P. Mendenhall, C. L. Morris, R. N. Mortensen, R. W. Pattie Jr., M. Pitt, B. Plaster, J. Ramsey, R. Rios, A. Sallaska, S. J. Seestrom, E. I. Sharapov, S. Sjue, W. E. Sondheim, W. Teasdale, A. R. Young, B. VornDick, R. B. Vogelaar, Z. Wang, and Yanping Xu

Citation: Review of Scientific Instruments 84, 013304 (2013); doi: 10.1063/1.4770063

View online: http://dx.doi.org/10.1063/1.4770063

View Table of Contents: http://scitation.aip.org/content/aip/journal/rsi/84/1?ver=pdfcov

Published by the AIP Publishing

\section{AlP Re-register for Table of Content Alerts}

\section{Create a profile.

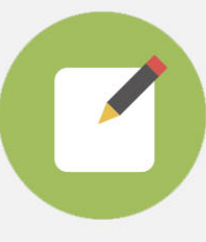




\title{
Performance of the Los Alamos National Laboratory spallation-driven solid-deuterium ultra-cold neutron source
}

\author{
A. Saunders, ${ }^{1}$ M. Makela, ${ }^{1}$ Y. Bagdasarova, ${ }^{1}$ H. O. Back, ${ }^{2}$ J. Boissevain, ${ }^{1}$ L. J. Broussard,${ }^{2}$ \\ T. J. Bowles, ${ }^{1}$ R. Carr, ${ }^{3}$ S. A. Currie, ${ }^{1}$ B. Filippone, ${ }^{3}$ A. García, ${ }^{4}$ P. Geltenbort, ${ }^{5}$ \\ K. P. Hickerson, ${ }^{3}$ R. E. Hill, ${ }^{1}$ J. Hoagland, ${ }^{2}$ S. Hoedl, ${ }^{4}$ A. T. Holley, ${ }^{2}$ G. Hogan, ${ }^{1}$ T. M. Ito, ${ }^{1,3}$ \\ Steve Lamoreaux, ${ }^{1,6}$ Chen-Yu Liu, ${ }^{7}$ J. Liu, ${ }^{3,8}$ R. R. Mammei, ${ }^{9}$ J. Martin, ${ }^{3,10}$ D. Melconian, ${ }^{11}$ \\ M. P. Mendenhall, ${ }^{3}$ C. L. Morris, ${ }^{1}$ R. N. Mortensen, ${ }^{1}$ R. W. Pattie, Jr., ${ }^{2}$ M. Pitt, ${ }^{9}$ B. Plaster, ${ }^{12}$ \\ J. Ramsey, ${ }^{1}$ R. Rios, ${ }^{13}$ A. Sallaska, ${ }^{4}$ S. J. Seestrom, ${ }^{1}$ E. I. Sharapov, ${ }^{14}$ S. Sjue, ${ }^{1,4}$ \\ W. E. Sondheim, ${ }^{1}$ W. Teasdale, ${ }^{1}$ A. R. Young, ${ }^{2}$ B. VornDick, ${ }^{2}$ R. B. Vogelaar, ${ }^{9}$ Z. Wang, ${ }^{1}$ \\ and Yanping $\mathrm{Xu}^{2}$ \\ ${ }^{1}$ Los Alamos National Laboratory, Los Alamos, New Mexico 87544, USA \\ ${ }^{2}$ Department of Physics, North Carolina State University, Raleigh, North Carolina 27695, USA \\ ${ }^{3}$ Kellogg Radiation Laboratory, California Institute of Technology, Pasadena, California 91125, USA \\ ${ }^{4}$ Department of Physics, University of Washington, Seattle, Washington 98195, USA \\ ${ }^{5}$ Institut Laue-Langevin, 38042 Grenoble Cedex 9, France \\ ${ }^{6}$ Department of Physics, Yale University, P.O. Box 208120, New Haven, Connecticut 06520-8120, USA \\ ${ }^{7}$ Department of Physics, University of Indiana, 727 E. Third St., Bloomington, Indiana 47405-7105, USA \\ ${ }^{8}$ Department of Physics, Shanghai Jiao Tong University, Shanghai 200240, China \\ ${ }^{9}$ Department of Physics, Virginia Tech, Blacksburg, Virginia 24061, USA \\ ${ }^{10}$ University of Winnipeg, Winnipeg, Manitoba R3B 2E9, Canada \\ ${ }^{11}$ Cyclotron Institute, Texas AM University, College Station, Texas 77843, USA \\ ${ }^{12}$ Department of Physics and Astronomy, University of Kentucky, Lexington, Kentucky 40506, USA \\ ${ }^{13}$ Department of Physics, Idaho State University, Pocatello, Idaho 83209, USA \\ ${ }^{14}$ Joint Institute for Nuclear Research, 141980 Dubna, Russia
}

(Received 25 July 2012; accepted 14 November 2012; published online 14 January 2013)

In this paper, we describe the performance of the Los Alamos spallation-driven solid-deuterium ultracold neutron (UCN) source. Measurements of the cold neutron flux, the very low energy neutron production rate, and the UCN rates and density at the exit from the biological shield are presented and compared to Monte Carlo predictions. The cold neutron rates compare well with predictions from the Monte Carlo code MCNPX and the UCN rates agree with our custom UCN Monte Carlo code. The source is shown to perform as modeled. The maximum delivered UCN density at the exit from the biological shield is 52(9) UCN/cc with a solid deuterium volume of $\sim 1500 \mathrm{~cm}^{3}$. (C) 2013 American Institute of Physics. [http://dx.doi.org/10.1063/1.4770063]

\section{INTRODUCTION}

Ultra-cold neutrons (UCN) are defined as neutrons that can be trapped in material bottles and guides because their kinetic energies are less than the effective potential $V_{F}$ (the volume average of the Fermi potential),

$$
V_{F}=\frac{2 \pi h^{2}}{m} N a
$$

where $N$ is the number density, $a$ is the material's neutron scattering length, and $m$ is the neutron mass. ${ }^{58} \mathrm{Ni}$ exhibits one of the largest potentials of available materials, $342 \mathrm{neV}$. Neutrons with kinetic energies below this potential (i.e., velocities below $8.09 \mathrm{~m} / \mathrm{s}$ ) can be trapped in a ${ }^{58} \mathrm{Ni}$ bottle. Two books and a recent review highlight the wide variety of physics that can be performed using trapped UCN. ${ }^{1-3}$

In the past decade, experiments have demonstrated several advantages of using ultra-cold neutrons for beta decay experiments. Measuring the decay of neutrons trapped in material bottles eliminates systematic errors associated with defining the volume and flux that have plagued neutron lifetime experiments with cold neutron beams ${ }^{4-7}$ and there- fore allows more precise measurements. ${ }^{8-13}$ More recently, results obtained with the Los Alamos Neutron Science Center (LANSCE) UCN source ${ }^{14,15}$ have demonstrated that the high polarizations and low backgrounds that can be obtained with spallation-driven, pulsed UCN sources can reduce the systematic errors in measuring the spin dependence of neutron beta decay ${ }^{16,17}$ relative to cold neutron beam-based experiments.

The idea that solid deuterium $\left(\mathrm{SD}_{2}\right)$ can used as a superthermal UCN source goes back to a paper by Golub and Boening. ${ }^{18,19}$ Pokotilovski pointed out the advantages of $\mathrm{UCN}$ production in $\mathrm{SD}_{2}$ at pulsed neutron sources; ${ }^{20}$ the use of spallation as a pulsed source for neutrons was suggested by the Gatchina group. ${ }^{21-23}$ New UCN sources, using superthermal production ${ }^{1}$ with either superfluid helium or solid deuterium as a converter material, are being built at several facilities. ${ }^{24-28}$ Recently, a very encouraging result has been published by Masuda for a prototype source based on production in superfluid helium. ${ }^{29}$

The lifetimes of UCN in solid ortho-deuterium are limited by the neutron's decay time, nuclear absorption of UCNs on the deuterium, nuclear absorption on contaminating hydrogen, thermal upscattering from the deuterium, 
and upscattering caused by spin conversion of contaminating para-deuterium. These lifetimes, measured in solid orthodeuterium at temperatures below $12 \mathrm{~K},{ }^{30}$ are long enough to yield high densities in a spallation driven source, in agreement with theoretical calculations, ${ }^{31}$ and correspondingly high densities were measured in a small scale prototype UCN source. ${ }^{32}$ UCN production rates in solid ortho-deuterium measured in experiments at $\mathrm{PSI}^{33}$ and at $\mathrm{LANSCE}^{34}$ have verified the earlier work in more quantitative and controlled experiments.

Here, we report on results that have been obtained with a spallation-driven pulsed UCN source, driven with protons provided by the $800 \mathrm{MeV}$ Los Alamos Neutron Science Center linear accelerator at the Los Alamos National Laboratory. The source moderates and converts spallation neutrons, produced in a tungsten target, to UCN in a windowless solid deuterium volume inside of a UCN guide system. The neutrons are transported through a stainless steel guide system to an experimental area where they can be used for experiments. In this paper, we describe the design of the source and measurements and predictions of the cold neutron and UCN production rates. We compare Monte Carlo predictions of the UCN transport times and flux through the guide system to their measured values, and use the validated Monte Carlo results to predict the densities available for experiments.

\section{DESIGN}

The details of the source are shown in the schematic drawing in Figure 1. Protons from the LANSCE $800 \mathrm{MeV}$ accelerator are delivered to a $12 \mathrm{~cm}$ long helium gas-cooled tungsten alloy-spallation target. Recently (2010), the target shape has been changed from a right circular cylinder $(2 \mathrm{~cm}$ diameter) to a target with an approximate square cross section with rounded corners with $2.5 \mathrm{~cm}$ sides in order to increase the amount of tungsten in the path of the proton beam. This has improved the produced UCN rates by $\sim 50 \%$. The target is surrounded by a room temperature beryllium reflector, in which a volume of $\mathrm{SD}_{2}$ is embedded. The $\mathrm{SD}_{2}$ volume, a vertical right circular cylinder $19.7 \mathrm{~cm}$ diameter and $5.7 \mathrm{~cm}$ high, is contained in a liquid- $2 \mathrm{~cm}$ thick liquid helium-cooled

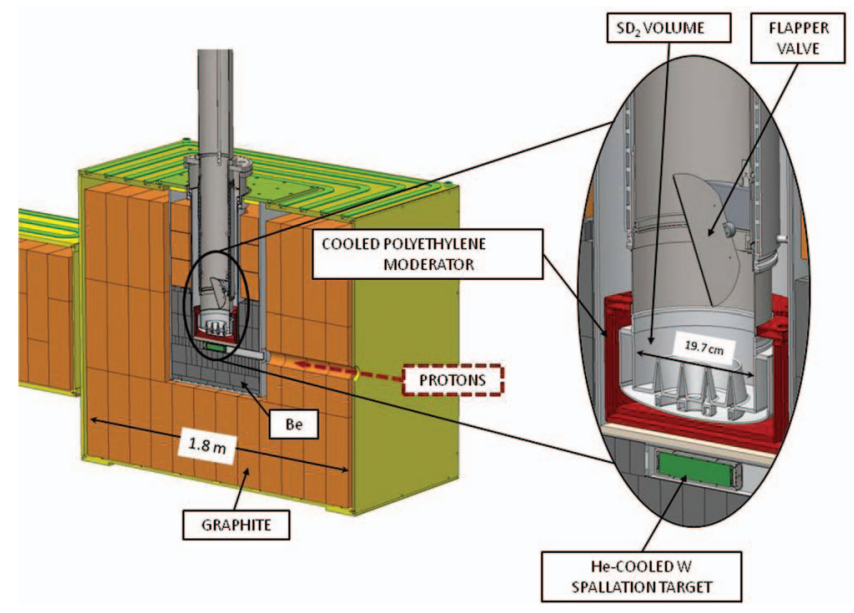

FIG. 1. Cutaway view of the source. The graphite cube is $1.8 \mathrm{~m}$ on a side. This entire assembly is surrounded by the biological shield, consisting of at least $3 \mathrm{~m}$ of steel and $2 \mathrm{~m}$ of concrete in all directions. aluminum cryostat that is coated with ${ }^{58} \mathrm{Ni}$ to reflect and contain the UCN. A set of fins (apparent in the inset in Figure 1) are machined in the bottom of the aluminum cryostat to improve the surface contact between the liquid helium and the solid deuterium. This entire assembly is surrounded by approximately $1 \mathrm{~m}$ of reactor grade graphite. Between the solid deuterium volume and the beryllium reflector is a $1 \mathrm{~cm}$ thick layer of polyethylene beads with an effective density of $0.5-0.6 \mathrm{~g} / \mathrm{cm}^{3}$, cooled by some of the boil off gas from the liquid helium that cools the $\mathrm{SD}_{2}$. The temperature of the polyethylene beads depended on the proton current delivered to the $\mathrm{W}$-target and was around $150 \mathrm{~K}$ at an average current of $5.8 \mu \mathrm{A}$.

Temperatures were typically measured using cernox sensors clamped to the aluminum outer wall of the guide vacuum chamber. These sensors provided reproducible and reliable temperatures with roughly a $1 \mathrm{~K}$ uncertainty. In the case of the polyethylene, the sensor was mounted to the outside of the aluminum can containing the polyethylene beads, and operational conditions (He vapor flow through the polyethylene) could vary significantly. This introduces a difficult to quantify but significant uncertainty into these temperature measurements. Measurements and MCNPX Monte Carlo calculations indicated only a weak dependence of the UCN production rate on the polyethylene temperature, because a significant amount of neutron moderation was provided by the $\mathrm{SD}_{2}$.

The aim of this design was to couple the solid deuterium volume as closely as possible to the spallation target in order to take advantage of the high neutron densities possible in spallation neutron production. Since only $\sim 20 \mathrm{MeV}$ of thermal energy is deposited in the target assembly for each spallation neutron produced, compared to $\sim 200 \mathrm{MeV}$ per neutron in a reactor, the cold neutron density in a spallation-driven source can be higher for a given cooling capability. However, because of the small spallation source volume, the cold neutron density in the $\mathrm{SD}_{2}$ would fall quickly if it were moved away from the spallation target. The technical challenge was to provide enough cooling to the solid deuterium to keep the temperature sufficiently low $(<\sim 10 \mathrm{~K})$ so as not to impact the UCN lifetimes in the target due to thermal upscatter, ${ }^{1}$ while the beam was on. The source of heating was both charged particles and gamma rays produced in proton beam-target interactions.

The lower part of the target was constructed from aluminum and an aluminum-beryllium alloy in order to keep the heat load from the target walls to a minimum. Thermal isolation between the solid deuterium volume and the upper target region was provided by an explosively bonded aluminum to stainless steel thermal break. The temperature of the UCN guide above the thermal break could be controlled by flowing boil-off helium gas from the $\mathrm{SD}_{2}$ cooling through a heat exchanger built into the outer target wall.

Biological shielding was provided by $\sim 2 \mathrm{~m}$ of steel and $1.8 \mathrm{~m}$ of concrete on the sides and top of the source box with somewhat more shielding on the downstream face. The shielding is sufficient to allow experimentalists to occupy the experimental area with up to $10 \mu \mathrm{A}$ of beam with no precautions other than standard dosimetry. 
The inside wall of the cryostat volume and vertical guide was sputter-coated with $200 \mathrm{~nm}$ of ${ }^{58} \mathrm{Ni}$. When the UCN exited the top surface of the $\mathrm{SD}_{2}$ into the vacuum in the guide, they received a potential boost of $102 \mathrm{neV}$; gravity was used to cancel this effect with a $1 \mathrm{~m}$ vertical section of $18 \mathrm{~cm}$ diameter guide before the stainless steel horizontal guide section that transported the UCN out of the biological shield wall. The $342 \mathrm{neV}$ potential of ${ }^{58} \mathrm{Ni}$ ensured that all of the neutrons that could be transported by stainless steel (potential $189 \mathrm{neV}$ ) into the experimental area were also trapped by the walls in the lower volume of the source.

A butterfly (flapper) valve, attached to the bottom of the vertical guide above the $\mathrm{SD}_{2}$, is also shown in Figure 1. This was actuated by a rotation shaft that exited from the top of the system and was driven by a stepping motor. The opening and closing time of the flapper valve was about $0.1 \mathrm{~s}$.

When in production, the peak proton current from the accelerator was typically $10 \mathrm{~mA}$ of protons, delivered in 5 pulses of length $625 \mu \mathrm{s}$ at $20 \mathrm{~Hz}$, with a gap between groups of pulses of $5.0 \mathrm{~s}$. The total charge delivered per pulse group was $30 \mu \mathrm{C}$ in $\sim 0.2 \mathrm{~s}$ for an average current of $150 \mu \mathrm{A}$ during the time when the UCN flapper valve was open. The longer term average current delivered to the target in this mode was $5.8 \mu \mathrm{A}$.

Previous design calculations ${ }^{14,35}$ predicted that the total number of cold neutrons $(\mathrm{CN})$ through the solid deuterium volume would be about $3 \mathrm{CN}$ per proton delivered to the tungsten target (this gave a cold neutron flux density of $\left.6 \times 10^{10} \mathrm{CN} / \mathrm{cm}^{2} / \mathrm{s} / \mu \mathrm{A}\right)$. The UCN production was predicted to be $250 \mathrm{UCN} / \mathrm{cm}^{3} / \mu \mathrm{C}$ inside the $\mathrm{SD}_{2}$ volume. Because the source performance fell below these expectations in early tests, we conducted measurements of the flux from the UCN source and performed new calculations with the latest MCNP5/MCNPX codes and their standard data libraries. ${ }^{36-38}$ These are described below.

\section{COLD NEUTRON PERFORMANCE}

Measurements of the cold neutron flux in the target volume were accomplished using two methods: (1) argon activation by the cold neutron flux and (2) direct counting cold and very cold neutrons with a ${ }^{3} \mathrm{He}$-based neutron detector of known efficiency in a time of flight experiment.

\section{A. Activated argon cold neutron flux measurement}

An argon-activation experiment was performed by freezing $15.2 \mathrm{~g}$ of natural isotopic abundance argon into the empty $\mathrm{SD}_{2}$ volume, delivering a small amount of proton charge through the tungsten target, and then recovering some of the gas and counting gamma rays produced by the beta decay of ${ }^{41} \mathrm{Ar}$. The argon gas was preloaded into an external calibrated loading volume of 7.91 at $1.3 \times 10^{5} \mathrm{~Pa}$ (Figure 2). This was subsequently opened to the source and UCN guides, and the temperature and pressure were allowed to equilibrate. The pressure after equilibration was $6.3 \times 10^{3} \mathrm{~Pa}$. The volume of the $\mathrm{SD}_{2}$ chamber, vertical guide, and horizontal guide was 1591 .

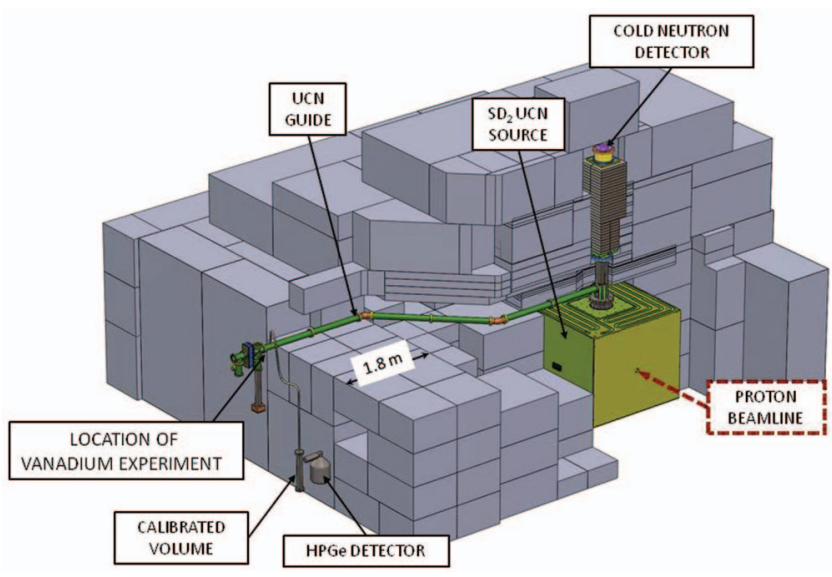

FIG. 2. Schematic layout of the argon activation experiment. Parts of the biological shield are removed in this figure so that the UCN transport is visible. The calibrated volume was used for loading, retrieving, and measuring the decay of the argon gas. The location where the vanadium foil experiment was performed is indicated.

The cryostat was then cooled to $60 \mathrm{~K}$ (freezing the argon into the empty cold $\mathrm{SD}_{2}$ volume of the cryostat) and exposed to the neutron fluence produced by $1.52 \times 10^{15}$ protons impacting the tungsten spallation target. The proton fluence was measured with a Bergoz coil ${ }^{39}$ to a precision of several percent. The polyethylene (cold moderator) temperature for this irradiation was $155 \mathrm{~K}$. After the irradiation, the cryostat was warmed until the pressure in the loading volume and UCN guide system was $4.9 \times 10^{3} \mathrm{~Pa}(82 \%$ recovery). The calibrated loading volume was closed off from the rest of the system, the remaining argon in the source and guides was pumped out, and the $1.2 \mathrm{MeV}$ gamma rays from the beta decay of ${ }^{41} \mathrm{Ar}\left(\mathrm{t}_{1 / 2}=126 \mathrm{~s}\right)$ in the calibrated loading volume were counted. A sample spectrum is shown in Figure 3.

The product of photopeak efficiency and effective solid angle for the high purity germanium (HPGe) detector was measured by mounting a ${ }^{60} \mathrm{Co}$ source of known activity at the loading volume location and comparing rates of the 1.17 and $1.33 \mathrm{MeV} \gamma$-ray peaks to the known decay rate. The finite source volume of the argon was accounted for by averaging the solid angle over the argon volume. From these measurements, the ${ }^{41} \mathrm{Ar}$ production rate per proton was calculated to

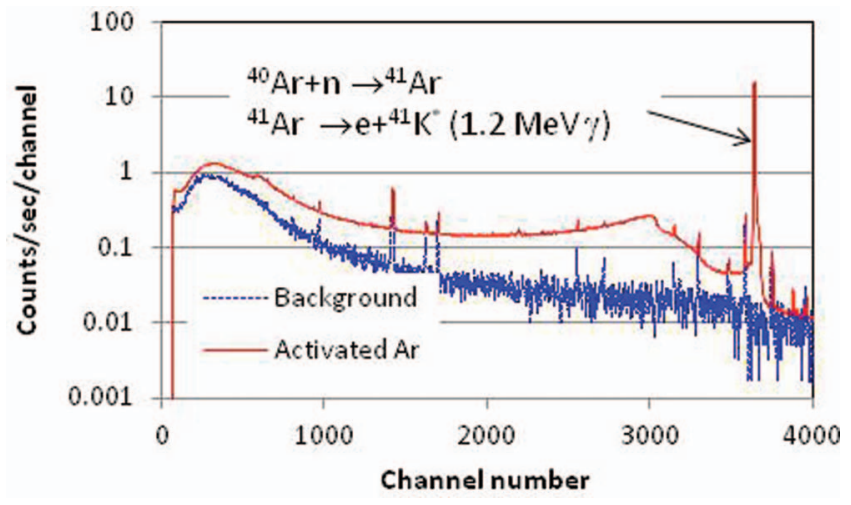

FIG. 3. Spectrum of gamma rays from the irradiated argon (red) and the background (blue). The main peak consists of the $1.2 \mathrm{MeV} \gamma$-rays from argon-41 decay. 
be $6.5 \times 10^{-4}$ integrated over the neutron spectrum. This can be compared to the MCNP prediction of $7.1 \times 10^{-4}$. The cold neutron fluence was calculated from these measurements, using the thermal neutron capture cross section of ${ }^{40} \mathrm{Ar}$ of 0.66 $\mathrm{b},{ }^{40}$ a $1 / v$ neutron velocity dependence of the cross section, the assumption of a Maxwellian neutron spectrum centered at the polyethylene moderator temperature of $155 \mathrm{~K}$, and a MCNP calculation of the relative contribution of cold neutrons to the argon- 41 activation of $60 \%$. This gave a cold neutron fluence of $0.84 \pm 0.17$ neutrons/proton through the $\mathrm{SD}_{2}$ source area in the absence of $\mathrm{SD}_{2}$, which corresponded to a flux density of $(1.7 \pm 0.3) \times 10^{10} \mathrm{CN} / \mathrm{cm}^{2} / \mathrm{s} / \mu \mathrm{A}$. The peak neutron flux was about $1.33 \times 10^{13} \mathrm{CN} / \mathrm{s} / \mathrm{cm}^{2}$. A $20 \%$ uncertainty, which dominated the total uncertainties quoted on these results, was assigned to account for our lack of knowledge of the exact geometry of the frozen argon in the $\mathrm{SD}_{2}$ volume.

\section{B. Time-of-flight (TOF) cold neutron flux measurement}

The time-of-flight experiment to benchmark the MCNP cold neutron flux was performed with a ${ }^{3} \mathrm{He}$-based neutron detector mounted on the top of the $2 \mathrm{~m}$ long iron and boratedpolyethylene laminated shielding plug that closed the biological shield package from the top. The plug had two open $2 \mathrm{~cm}$ diameter vertical channels: one with a $0.75 \mathrm{~mm}$ aluminum window and the other with a $2 \mathrm{~mm}$ pyrex window, each $2 \mathrm{~m}$ from the detector. The detector viewed the cold neutron flux through both channels. The length of the neutron flight path in this geometry was $3.60 \mathrm{~m}$. The limiting solid angle was the $2 \mathrm{~cm}$ diameter aperture immediately below the detector, with a solid angle of $2.4 \times 10^{-5} \mathrm{sr}$. The calculated efficiency of the detector for $25-\mathrm{meV}$ neutrons was 0.19 . A pulse-height spectrum from the detector in a typical cold neutron detection run is shown in Figure 4. For these measurements, protons were delivered to the tungsten spallation target in $250 \mathrm{~ns}$ long pulses of $\sim 1.4 \times 10^{10}$ protons at a rate of one pulse per second. As in the argon-activation measurements described above, the proton fluence was measured with a Bergoz coil. The arrival of pulses from the neutron detector (TOF) was measured as a function of time after the proton pulse. A typical TOF distribution with the polyethylene at a temperature of $220 \mathrm{~K}$, measured with the source empty (no solid deuterium), is shown in Figure 5.

Figure 5 also shows the time-of-flight distribution measured with $1000 \mathrm{cc}$ of solid deuterium at a temperature of $5 \mathrm{~K}$ in the cryostat and with a polyethylene temperature of $60 \mathrm{~K}$. The distribution demonstrates a considerable enhancement of the relative population of neutrons with a time of flight longer than $3.35 \mathrm{~ms}$, which corresponded to an energy below $6 \mathrm{meV}$. The total number of protons delivered to the tungsten target in this run was $5.7 \times 10^{13}$. Deducing the shape of the cold neutron energy spectrum from these data required a complicated deconvolution of the TOF-spectrum due to the energydependent moderation time in the source $(400-600 \mu \mathrm{s})$, which dominated the resolution function. This width was comparable to the width of the measured spectrum. The inte-

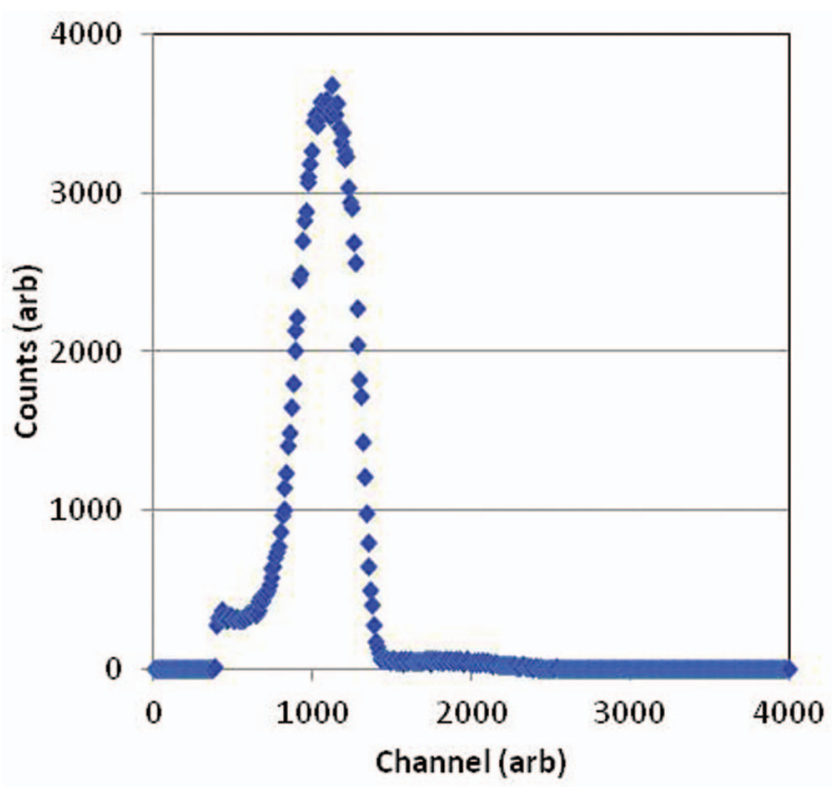

FIG. 4. Pulse-height spectrum from the 3 He-based neutron detector used for the $\mathrm{CN}$ and very cold neutron time-of-flight measurements. The measurements can be observed to be very clean.

gral over the spectrum, however, did not depend on the resolution function; therefore, it could be directly compared with the MCNP modeling. We performed such a comparison for neutron flux at the detector position after taking account of the energy-dependent ${ }^{3} \mathrm{He}$ detector efficiency. For the first spectrum, the integral of neutrons with energy below $100 \mathrm{meV}$ was $1.56 \times 10^{5}$ neutrons per $\mu \mathrm{C}$ of protons, while the corresponding MCNP prediction was $1.70 \times 10^{5}$ per $\mu \mathrm{C}$. For the second spectrum, the integrals below $25 \mathrm{meV}$ were $0.75 \times 10^{5}$ per $\mu \mathrm{C}$ of protons measured and $0.86 \times 10^{5}$ per $\mu \mathrm{C}$ predicted. In both cases the agreement is within $20 \%$.

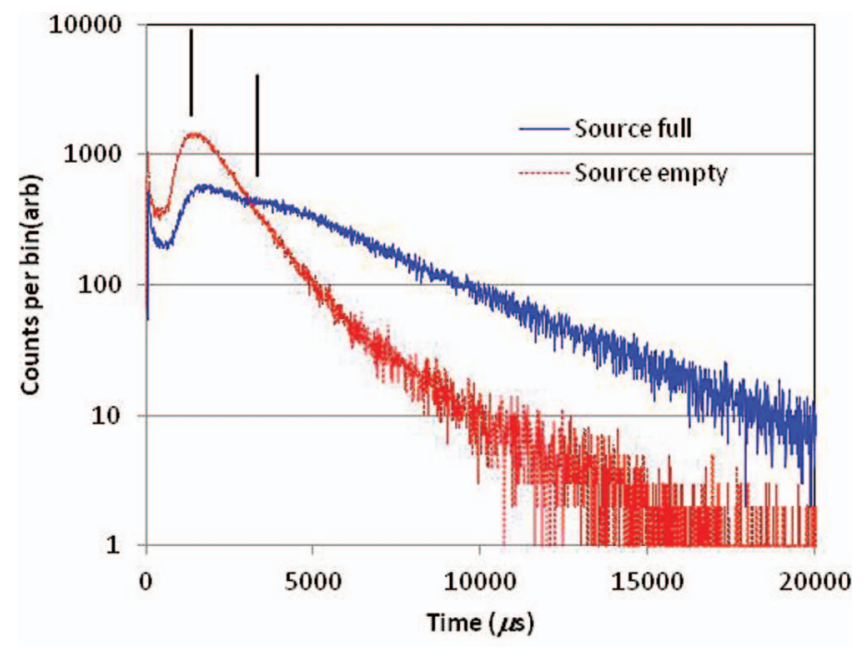

FIG. 5. Time-of-flight spectrum with the source empty and the polyethylene moderator at $220 \mathrm{~K}$ (red) and the source full of $\mathrm{SD}_{2}(\sim 1.21)$ and the polyethylene at a temperature of $60 \mathrm{~K}$ (blue). The time of the proton pulse corresponds to time $=0$. The total number of protons delivered through the tungsten target in this run was $5.2 \times 10^{13}$. The volume of the target was $\sim 1000 \mathrm{cc}$. The vertical black lines mark neutron energies of $40 \mathrm{meV}$ and $6 \mathrm{meV}$ at times of $1350 \mu \mathrm{s}$ and $3350 \mu \mathrm{s}$, respectively. 
The MCNP simulation was performed with the codes MCNP5 $^{38}$ and MCNPX. ${ }^{37}$ We used the $S(\alpha, \beta)$ option of the MCNP cross sections for $\mathrm{SD}_{2}$, graphite, and beryllium, and the Maxwellian MCNP gas model cross sections for other materials, including polyethylene. The MCNP5 data library does not have polyethylene kernels for temperatures below $300 \mathrm{~K}$. We therefore were forced to use the MCNP gas model for temperatures other than ambient. In order to estimate the systematic effect of making this change, we made comparison calculations (with $\mathrm{SD}_{2}$ in the cryostat) using the MCNP gas model for the $150 \mathrm{~K}$ polyethylene kernel and MCNP5's $20 \mathrm{~K}$ methane kernel (with the density modified to achieve an equal concentration of hydrogen atoms in the materials). The methane calculation showed a $25 \%$ increase in the cold neutron flux relative to the $150 \mathrm{~K}$ polyethylene calculation, thus putting an upper limit on the effect of using the $150 \mathrm{~K}$ gas model instead of the desired polyethylene kernel.

We used the geometry for the LANL ultra-cold neutron source developed by $\mathrm{Xu},{ }^{41}$ which takes into account all essential features of the setup shown in Figure 1. The tight collimation in the cold neutron flux measurement prevented a direct MCNPX modeling of the absolute detector rates. Instead, a two stage procedure was applied. First, the cold neutron flux leaving the $\mathrm{SD}_{2}$ surface was modeled by MCNPX in a standard way with a volume proton source. ${ }^{41}$ Next, the solid angle of the collimator-detector system was modeled using MCNP5 with a surface cold neutron source.

\section{UCN PRODUCTION}

The production of UCN in solid deuterium was measured in the experimental setup shown in Figure 6. The source was cooled and filled with solid deuterium. A detector was installed in the vertical UCN guide that led up from the $\mathrm{SD}_{2}$. It was located about $165 \mathrm{~cm}$ above the bottom of the source. The detector had two active regions, each $2.2 \mathrm{~cm}$ thick separated by a thin nickel foil. The active area of the detector was $7.8 \pm 0.2 \times 7.8 \pm 0.2 \mathrm{~cm}^{2}$. Because of the Fermi potential of the nickel, the second detector saw no UCN.

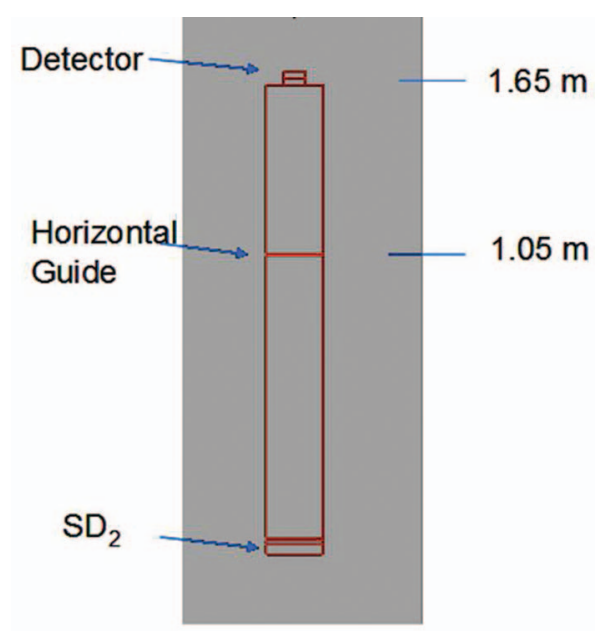

FIG. 6. Geometry used in the simulations of the internal measurement of $\mathrm{UCN}$ production in the $\mathrm{SD}_{2}$.

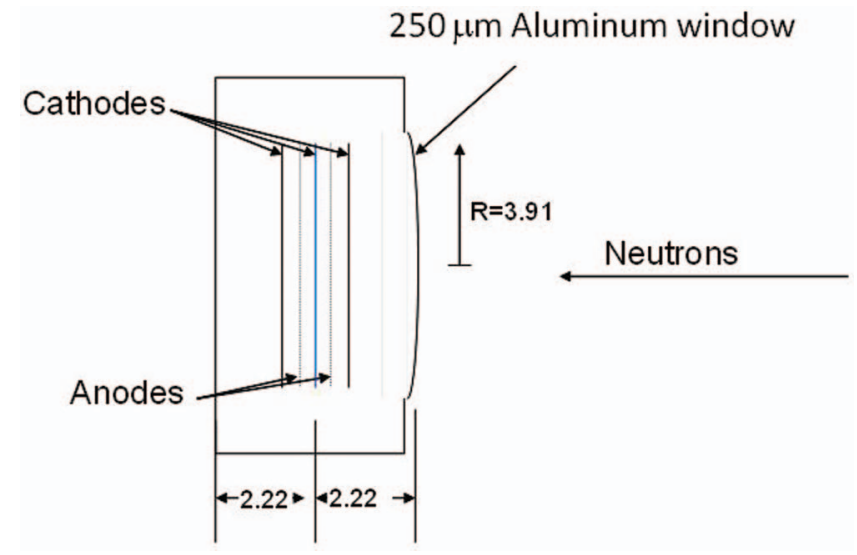

FIG. 7. Schematic view of the detector. Unlabeled dimensions are in $\mathrm{cm}$. The anode/cathode spacing was $0.4 \mathrm{~mm}$. the center cathode, blue line, was constructed of $25 \mu \mathrm{m}$ thick natural nickel foil. The analysis here used the front detector.

The detector was filled with a gas mixture of $8 \times 10^{4} \mathrm{~Pa}$ of $\mathrm{CF}_{4}$ and $(1.00 \pm 0.01) \times 10^{3} \mathrm{~Pa}$ of ${ }^{3} \mathrm{He}$. A schematic diagram of the detector is shown in Figure 7. The tungsten target was irradiated with proton pulses and the arrival time of pulses from the detector was measured as a function of time after the proton pulse. The detector response was modeled by tallying only neutrons that were absorbed in the gas. The lifetime for absorption was determined by the ${ }^{3} \mathrm{He}$ pressure to be $3.2 \mathrm{~ms}$.

The detector was configured with an internal voltage divider to place the cathode planes at $1 / 3$ of the potential of the anode planes using a string of $100 \mathrm{M} \Omega$ resistors. The cathodes were bypassed to ground through $1 \mathrm{nF}$ capacitors. The outer cathodes were constructed from electro-formed nickel grids with $97 \%$ open area. The inner cathode was a solid $25 \mu \mathrm{m}$ thick nickel foil. The anode/cathode spacing was $0.4 \mathrm{~mm}$.

The detector was operated at an anode voltage of $3400 \mathrm{~V}$ to provide sufficient anode gain to ensure a good signal-to-noise ratio while driving the $4.5 \mathrm{~m}$ of coaxial cable needed to get the signal out of the shielding package. The signals were amplified in a fast $(200 \mathrm{MHz})$ amplifier with a gain of $\sim 20$, and then in an Ortec timing filter amplifier. An integration time of $50 \mathrm{~ns}$ and a differentiation time of $500 \mathrm{~ns}$ gave good signal-to-noise performance.

The detector was separated from the internal volume of the UCN guide by a nickel barrier with a potential of $242 \mathrm{neV}$, a lifetime of $3.2 \times 10^{-4} \mathrm{~s}$, and a thickness of $25 \mu \mathrm{m}$. The $\mathrm{SD}_{2}$ was modeled with a potential of $108 \mathrm{neV}$ and total lifetime for $\mathrm{UCN}$ of $2.0 \times 10^{-2} \mathrm{~s}$. The internal guide was modeled with a Fermi potential of $342 \mathrm{neV}$, a non-specularity of 0.025 , and a loss per bounce of $2.8 \times 10^{-5}$.

Data were taken with a $625 \mu$ s long beam gate, delivered at a rate of one beam gate every $30 \mathrm{~s}$. Within each beam gate, the protons were delivered in micropulses and separated (leading edge to leading edge) by $1.788 \mu \mathrm{s}$. The charge in each beam pulse was about $0.5 \mu \mathrm{C}$. The time of arrival distribution in the front detector is shown in Figure 8.

In the calculation, neutrons were chosen from a $v^{2} d v$ distribution up to $200 \mathrm{~m} / \mathrm{s}$. Arrival times at the detector were 


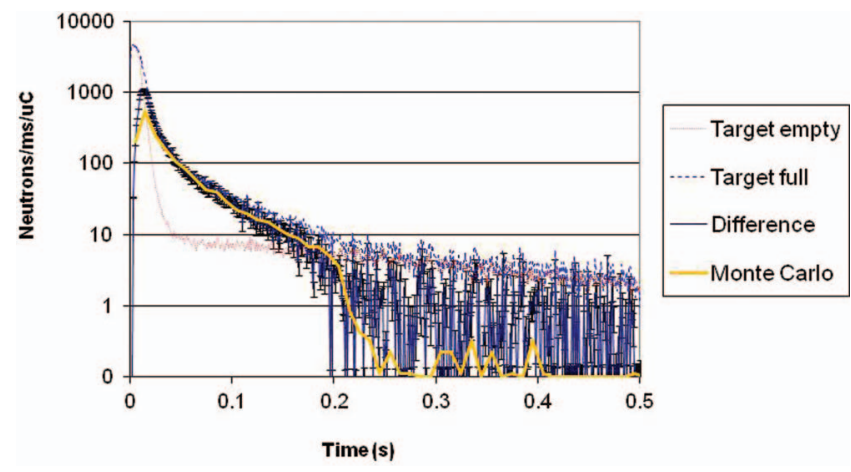

FIG. 8. Comparison of data to Monte Carlo calculations of UCN arrival time at the front detector. These data were taken with an $\mathrm{SD}_{2}$ volume of $1500 \mathrm{~cm}^{3}$.

tallied. The resulting spectrum was normalized to the data, and the normalization was used to determine the production rate of neutrons with velocities below $8 \mathrm{~m} / \mathrm{s}$. The normalized distribution is shown along with the data in Figure 8. Data were taken with deuterium in the target and with the target empty. These are also shown in Figure 8.

The transport of neutrons to the detector was predicted with a Monte Carlo calculation assuming a Maxwellian energy distribution in the solid deuterium and was normalized to the difference between full and empty. The result is shown in Figure 8. The cut off near $0.2 \mathrm{~s}$ corresponds to the flight time expected for $219 \mathrm{nV}$ neutrons at the surface of the $\mathrm{SD}_{2}$, the minimum energy needed to overcome the sum of the gravitational and the aluminum barrier potential to make it into the detector. The production rate of UCN (Neutrons with kinetic energies below (380-109 neV) in the solid deuterium, neutrons that are trapped by a $58 \mathrm{Ni}$ potential after they receive a $109 \mathrm{neV}$ boost on exiting from the solid deuterium) can be obtained by integrating the distribution. The resulting production density is $85 \pm 10 \mathrm{UCN} / \mu \mathrm{C} / \mathrm{cm}^{3}$.

On the other hand, relying on our successfully benchmarked (see Sec. III) MCNP5 prediction of cold neutron flux, we have simulated the cold neutron spectrum for the source. It is shown in Figure 9. The temperature of the polyethylene in this case is $150 \mathrm{~K}$. A visible structure is produced by the MCNP data file for solid deuterium at $20 \mathrm{~K}$. The fluence av-

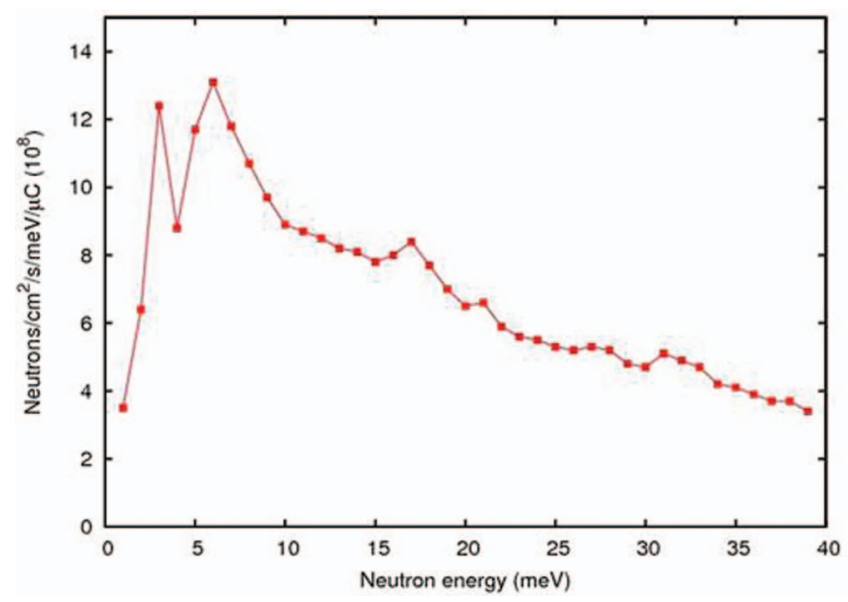

FIG. 9. MCNP simulated cold neutron flux for the LANL ultra-cold neutron source. eraged over the $\mathrm{SD}_{2}$ volume is $2.0 \times 10^{10} / \mathrm{cm}^{2} / \mu \mathrm{C}$ for neutron energies below $25 \mathrm{meV}$ (this is the energy range effective for the UCN production ${ }^{42}$ ). We find good agreement between this prediction and the result obtained from argon activation. With this spectrum, with the deuterium molecular number density of $3 \times 10^{22} \mathrm{~cm}^{-3}$ and with the UCN spectral (in the dependence of the cold neutron energy) production cross sections measured by Atchison, ${ }^{42}$ we have calculated the UCN production density to be $107 \pm 20 \mathrm{UCN} / \mu \mathrm{C} / \mathrm{cm}^{3}$, in reasonable agreement with the experimental result of $85 \pm 10 \mathrm{UCN} / \mu \mathrm{C} / \mathrm{cm}^{3}$. With an average proton beam current of $5.8 \mu \mathrm{A}$ and a peak current of $120 \mu \mathrm{A}$, the source in principle can achieve a peak UCN density of $10000 \mathrm{UCN} / \mathrm{cm}^{3}$. In fact, since the volume of the $\mathrm{SD}_{2}$ only fills $1 / 3$ of the volume below the flapper valve, the actual peak densities were only observed to be $3000 \mathrm{UCN} / \mathrm{cm}^{3}$.

We note also that in the latest in-beam study at LANSCE,${ }^{34}$ the UCN effective production cross section was measured to be $1.27 \times 10^{-7} \mathrm{~b}$ per molecule for the UCN energy range of $0-300 \mathrm{neV}$, in agreement with the cross sections of Atchison, ${ }^{33}$ when these are integrated over the neutron spectrum from LANSCE flight path FP-12, which is characterized by the neutron temperature of $35 \mathrm{~K}$.

The current results can also be compared with previous measurements of the UCN production in our prototype source of $460 \pm 90 \mathrm{UCN} / \mu \mathrm{C} / \mathrm{cm}^{3},{ }^{32}$ a factor of $4.3 \pm 1.2$ higher than our measurements of the present source. The prototype source $\mathrm{SD}_{2}$ volume had a diameter of $8 \mathrm{~cm}$, a solid polyethylene moderator cooled to $4 \mathrm{~K}$, and a beryllium reflector cooled to $77 \mathrm{~K}$. MCNP modeling suggests the smaller volume and different aspect ratio of the prototype $\mathrm{SD}_{2}$ volume gives a factor of two higher density when compared to the present source. The remaining difference of a factor of two is probably due to the combined effects of a different design and performance of the polyethylene moderator, to different absorption of cold neutrons in the construction materials, and to the larger tungsten spallation target used in the prototype. ${ }^{32}$

\section{TRANSPORT}

Measurements of the UCN flux external to the biological shield package were used to characterize the overall source and guide performance. The drawings in Figure 10 show the configuration used for these measurements. The flux from the source could be measured using the main detector by opening the gate valve (labeled in the figure). For normal operation, the proton beam was delivered in groups of five $625 \mu$ s pulses delivered at $20 \mathrm{~Hz}$ with a spacing between groups of $5 \mathrm{~s}$. This is illustrated in the graph shown in Figure 10. The average current in these measurements, measured using the Bergoz coil, was limited to about $5.0 \mu \mathrm{A}$ by the accelerator safety system.

The neutron flux and the lifetime of UCNs in the source and guides were measured by using UCN detectors ${ }^{43}$ external to the shield wall. The transport properties of the source were benchmarked using two measurements. In the first, the gate valve was closed and protons were delivered to the target at a rate of 1 group of pulses per $60 \mathrm{~s}$. Measurements were made 


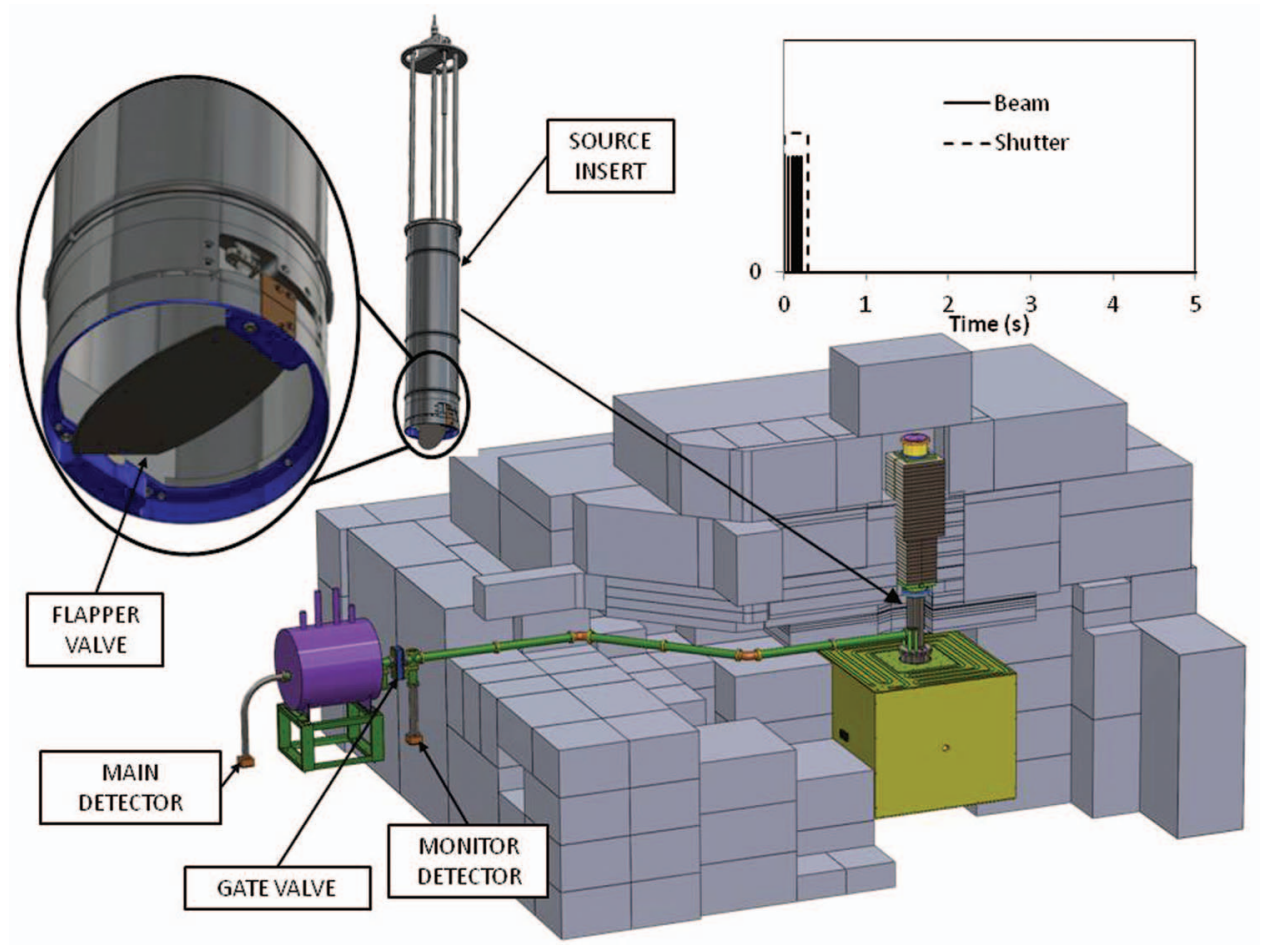

FIG. 10. Experimental configuration used to measure the external source performance. The inset at the left shows the details of the flapper valve. The graph in the upper right shows beam and shutter timing for normal operation.

for three states of the flapper valve: open, closed, and flapping. In the flapping state, the flapper was open at the beginning of the pulse group and closed at the end. Opening and closing times were $\sim 0.1 \mathrm{~s}$. The total time opened was $\sim 0.5 \mathrm{~s}$.

The source was modeled with a Monte Carlo transport code that included gravitational, magnetic, and material potentials. The system was modeled using a series of connected right circular cylinders. Each cylinder was characterized by a wall Fermi potential, a loss per bounce, a non-specularity fraction, an internal bulk potential, a spin-dependent potential, and a scattering length. The source was modeled by picking a starting point and direction for neutrons in the $\mathrm{SD}_{2}$ and transporting them by calculating the intersections of their parabolic trajectory with guide boundaries. At the intersection, they were either absorbed, reflected specularly, reflected diffusely (into a $\cos (\theta)$ angular distribution, where $\theta$ is measured with respect to the normal from the guide), or passed into a connected guide section. The connections between guides could be opened or closed at different times. This model did not include more quantum mechanical detailed models of reflection and transmission from potential barriers or of scattering from rough surfaces.

Plots of the rate of UCNs measured in the monitor detector for the flapper-open run are shown in Figure 11 and for the flapper-closed run are shown in Figure 12. The arrival time distribution at early times was sensitive to the non-specularity of the guide surfaces. A single non-specularity parameter was used for all of the guides in the model, and this was adjusted to fit the region between 1 and $10 \mathrm{~s}$ in the data presented in Figure 11. Monte Carlo predictions as a function of the non-specularity and the loss per bounce are also shown in Figures 11 and 12. A best fit of 3.0(5) $\times 10^{-2}$ and 3.5(1) $\times 10^{-4}$ were obtained for the non-specularity and the loss per bounce, respectively.

A potential of $100 \mathrm{neV}$, a neutron lifetime of $30 \mathrm{~ms}$, and a scattering length of $4 \mathrm{~cm}$ were used for the solid deuterium. These were calculated knowing the fraction of ${ }^{1} \mathrm{H}^{2} \mathrm{H}$ molecules contaminating the ${ }^{2} \mathrm{H}_{2}$ in the cryostat (the H-D fraction), the density of the deuterium, and the ratio of orthoand para-spin states of the deuterium. The normal values of these parameters were $2.0 \times 10^{-3}$ for the hydrogen- 1 contamination, $0.2 \mathrm{~g} / \mathrm{cm}^{3}$ for the density of the $\mathrm{SD}_{2}$, and $1.0 \%$ for the para-deuterium contamination. The H-D fraction was supplied by the manufacturer of the gas, the density was obtained from Silvera, ${ }^{44}$ and the para-deuterium fraction was measured using Raman scattering ${ }^{45}$ from a gas sample. Conversion of

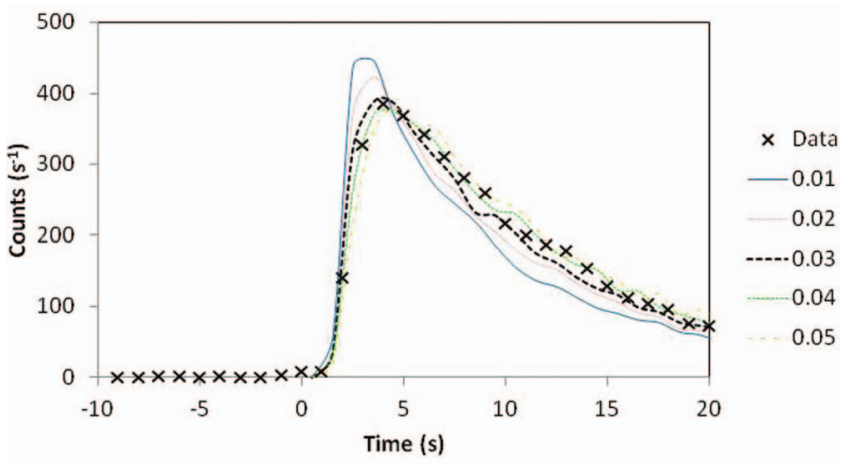

FIG. 11. UCN lifetime measurements with the flapper valve open. The data here and in Figures 13 and 14 were taken with $\sim 1.21$ of $\mathrm{SD}_{2}$ in the source. The data were measured with a spacing between proton pulses of $100 \mathrm{~s}$. The curves show the Monte Carlo predictions for different values of the guide non-specularity given in the legend. 


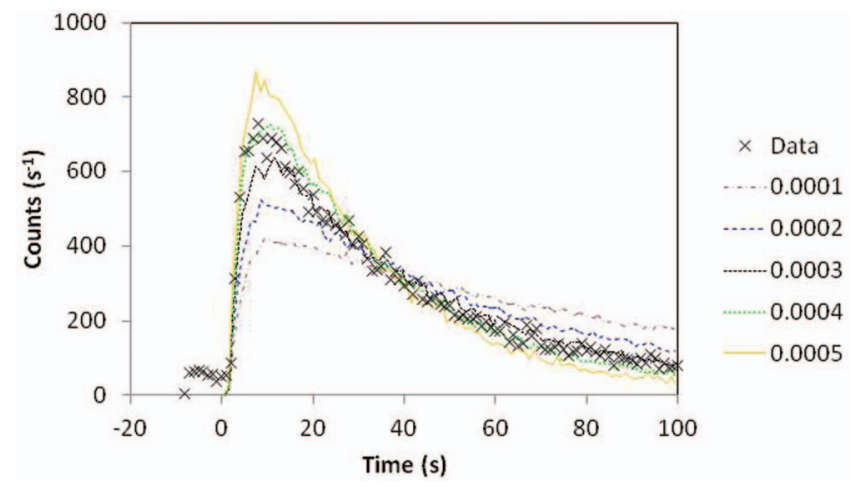

FIG. 12. Flapper closed lifetime measurement. The solid lines show Monte Carlo predictions for different loss per bounce values. For these measurement the proton pulse spacing was $100 \mathrm{~s}$. The counts before time $=0$ are neutrons wrapping around from the previous pulse. The different curves are predictions for different values of the loss per bounce given in the legend.

the para-deuterium from the room temperature fraction of $1 / 3$ was accomplished by using a catalytic converter ${ }^{45}$ which achieved $\sim 4 \%$ and then by irradiating the source with the proton beam, which lowered the fraction to $\sim 1 \%$ after $\sim 1$ week of running at an average proton current of $4 \mu \mathrm{A}$.

The surface of the $\frac{1}{2}$ in. VCR connection to the monitor connector was not well determined. It was modeled as a vertical section $7 \mathrm{~cm}$ long of $1 \mathrm{~cm}$ diameter guide with a non- specularity of unity. This was checked by comparing the counting rate in the monitor detector with that in a $7.5 \mathrm{~cm}$ diameter guide coupled through a super conducting magnet, the prepolarizer magnet (PPM), that normal held a magnetically embedded aluminum foil that decoupled the source vacuum from the experiment vacuum while polarizing the UCN neutron beam. Measurements of the two monitor counting rates along with the Monte Carlo predictions are shown in Figure 13. This ensures that the transport into the monitor detector is

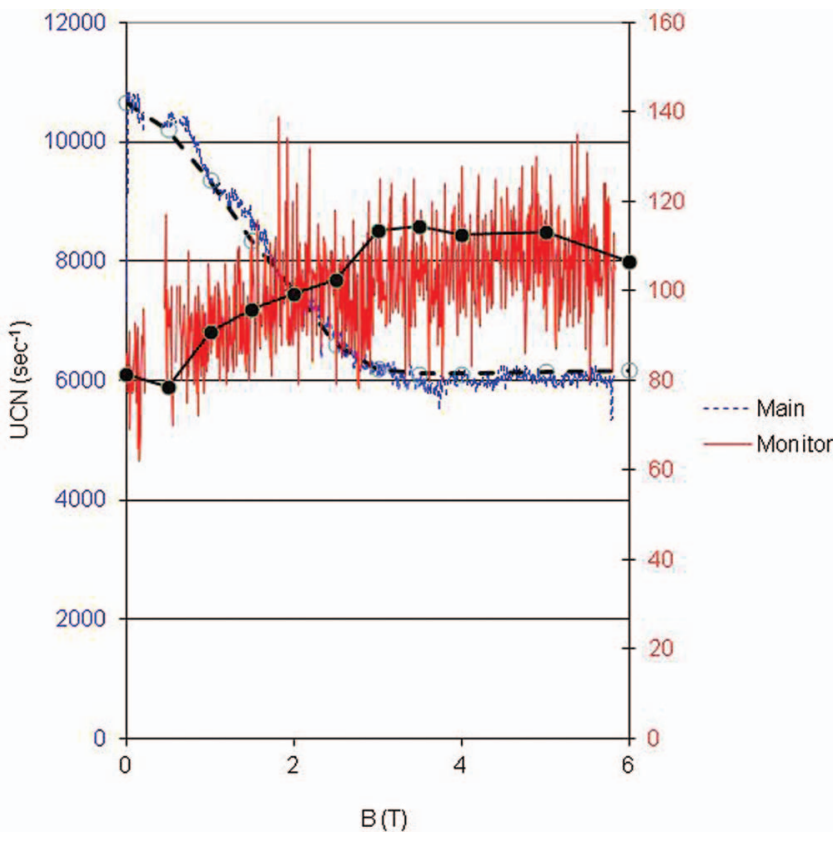

FIG. 13. Main (blue) and monitor (red) detector counting rates as a function of the magnetic field in the pre-polarizer magnet. The black curves show the Monte Carlo predictions. understood to the same level as the transport into the main detector.

The efficiency of the UCN detectors included several terms: losses in the windows (measured to be $\sim 50 \%$ ), losses due to wall effects (measured to be $20 \%$ ), thermal upscattering of UCNs from the $\mathrm{CF}_{4}$ (calculated to be 20\%), and geometric loss (calculated to be $12 \%$ ). The net UCN monitor detector efficiency was $0.28(5) \%$.

This model of the source was applied to data taken during the 2009 and 2010 LANSCE accelerator cycles. Between these two cycles, the tungsten spallation target was changed from a cylinder to a "D" shape that had about twice the mass and was expected to produce more spallation neutrons. The number of neutrons produced in the $\mathrm{SD}_{2}$ per $\mu \mathrm{C}$ of incident proton fluence was adjusted in the model to reproduce the measured monitor counting rate with the gate valve closed. This gave $60(12) \mathrm{UCN} / \mu \mathrm{C} / \mathrm{cm}^{3}$ for the 2009 target and $100(20) \mathrm{UCN} / \mu \mathrm{C} / \mathrm{cm}^{3}$ for the 2010 target The normalization for the old target compares well with the number measured with the internal detector of $85 \pm 10 \mathrm{UCN} / \mu \mathrm{C} / \mathrm{cm}^{3}$ and also agrees with the cold neutron density measurements when they are integrated over the UCN production cross sections.

The neutron density in the UCN guide achieved external to the shielding wall with the gate valve closed was $48(10)$ $\mathrm{UCN} / \mathrm{cm}^{3}$ in 2009 and 79(16) in 2010. The model was used to simulate the transport of UCN though the polarizing system and into the superconducting spectrometer (SCS) that used for UCNA. ${ }^{40}$ Significant loss in the density occurred in this transport because of the polarization; losses in the high magnetic field regions of the two polarizing guides; losses in SCS, where the neutron lifetime was comparable to the loading time of the SCS UCN trap; and losses due to entering the $1 \mathrm{~T}$ magnetic field in the SCS. Figure 14 shows how the density evolved through the transport system. The predicted density achieved in the SCS, obtained by normalizing the calculation to the monitor detector, was $2.0(4) \mathrm{UCN} / \mathrm{cm}^{3}$ and the predicted beta decay rate was $60(12)$, which agreed well with the measured decay rate of 40-60, with a peak of 60 . This provided an absolute check on the predicted densities inferred from the Monte Carlo calculations and the agreement was good.

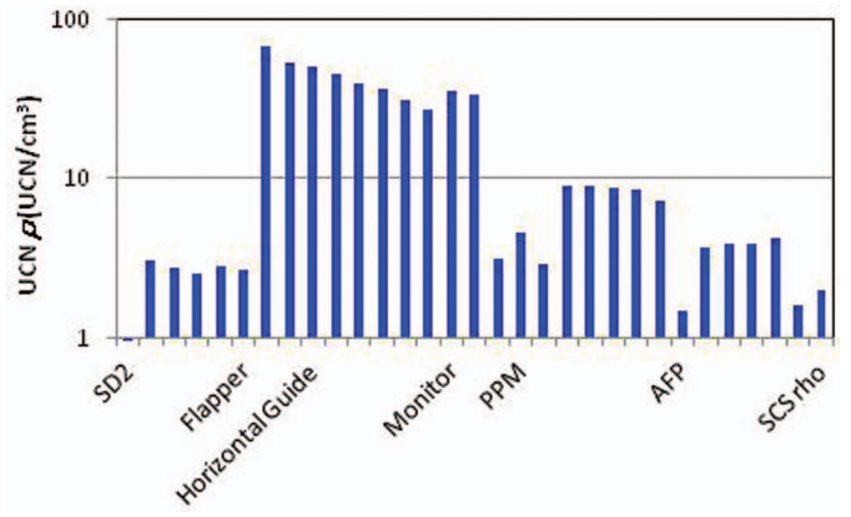

FIG. 14. UCN density in the transport elements between the source and the SCS. There are three super conducting magnets in the transport, the PPM with a 6 T field, the Adiabatic Fast Passage spin processor magnets with a short section of $7 \mathrm{~T}$ field and a gradient section of $1 \mathrm{~T}$, and the SCS with a $1 \mathrm{~T}$ field. 


\section{DIRECT MEASUREMENT OF THE UCN DENSITY}

The flux of UCN at the guide wall at the exit from the source was measured by affixing a $1 \mathrm{~cm}$ diameter, $250 \mu \mathrm{m}$ thick vanadium foil to the guide wall, see Figure 2, outside of the biological shield and upstream of the gate valve. This is just below a $1.2 \mathrm{~cm}$ diameter port that is used for experiments. This is just below a UCN port that is being used for an experiment aimed at measuring the Fertz term in neutron beta decay. Gamma rays from the decay of ${ }^{52} \mathrm{~V}$, formed by neutron capture on ${ }^{51} \mathrm{~V}$, were measured in a $\mathrm{HpGe}$ detector and used to calculate the UCN flux at the guide wall. The negative Fermi potential of vanadium of $-7 \mathrm{neV}$ ensures incident neutrons enter the foil with high probability and the large thermal neutron capture cross section of $5.08 \mathrm{~b}$, resulting in a neutron life time of $1.2 \times 10^{-5}$, implies nearly all neutrons that enter the foil will be captured.

The efficiency solid angle product for the detector was obtained by extrapolating a measurement of the $1173 \mathrm{keV}$ and the $1332 \mathrm{keV}$ lines from a calibrated ${ }^{60} \mathrm{Co}$ source to $1434 \mathrm{keV}$, the energy of the most prominent line from the decay of ${ }^{52} \mathrm{~V}$, with data taken in the same geometry as the vanadium foil measurement. The solid angle-efficiency product of the detector was $2.8 \times 10^{-2}$. Data were obtained after the beam was on for several lifetimes of ${ }^{52} \mathrm{~V}, 324 \mathrm{~s}$, to ensure that production and decay of ${ }^{52} \mathrm{~V}$ were in equilibrium. A typical spectrum is shown in Figure 15.

The ${ }^{52} \mathrm{~V}$ production rate, $R$, was measured to be $\mathrm{R}=1.82(18) \times 10^{3} \mathrm{~s}^{-1}$ with a gate valve detector rate of 318 $\mathrm{UCN} / \mathrm{s}$. If this is taken as the UCN flux into the area of the foil, the UCN density can be calculated using kinetic theory as: $\rho_{\mathrm{UCN}}=\frac{4 R}{a \bar{v}}$, where $\bar{v}=390 \mathrm{~cm} / \mathrm{s}$ is the average neutron velocity and $a$ is the area of the foil. This gives a density of $44(5) \mathrm{UCN} / \mathrm{cm}^{3}$ when normalized to the gate valve monitor rate $586 \mathrm{~s}^{-1}$, obtained when the source and beam are optimally tuned.

There are two corrections made to this density. The first is due to thermal up-scatter that competes with absorption of

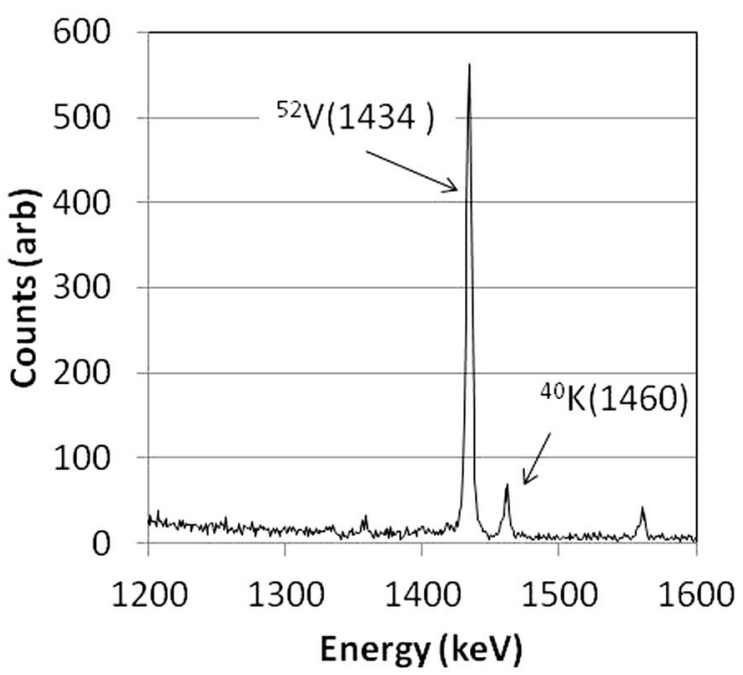

FIG. 15. Gamma ray spectrum showing the $1434 \mathrm{keV}$ line from the decay of ${ }^{52} \mathrm{~V}$.

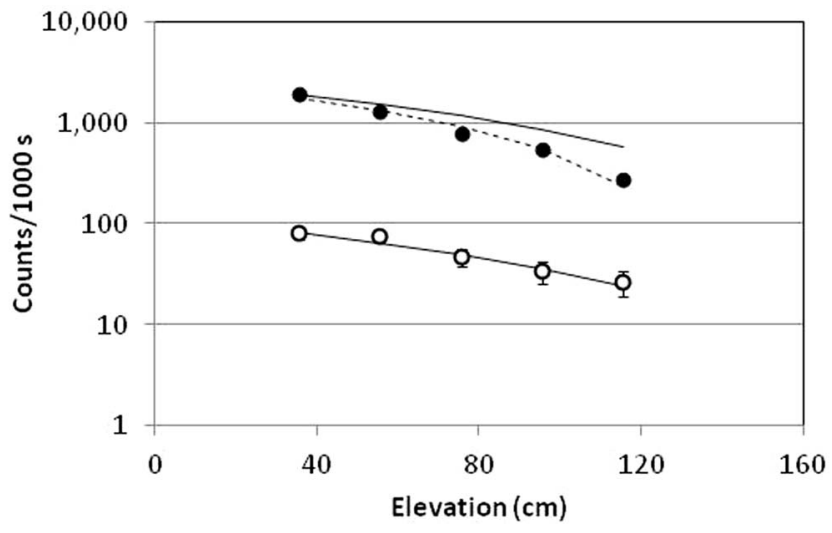

FIG. 16. Solid points: ${ }^{52} \mathrm{~V}(1444 \mathrm{keV})$. Open points: $(\mathrm{n}+\mathrm{p} \rightarrow \mathrm{d}+\gamma(2220$ $\mathrm{keV})$. The solid lines are $\mathrm{v}^{2}$ distribution normalized to the data, where $\mathrm{v}$ is the neutron velocity. The dashed line shows the corrected distribution described in the text.

UCN. We have measured the up-scatter lifetime by comparing the rates of up scattered neutrons measured in a bare ${ }^{3} \mathrm{He}$ proportional chamber external to a UCN guide with equal areal polyethylene and vanadium foils mounted inside of the vacuum system. Polyethylene was assumed to be a near perfect upscatterer. The ratio of the rates was 0.02 giving a correction factor of 1.02(2). The second correction arises from the oxide layer known to form on the surface of vanadium. The potential of $\mathrm{V}_{2} \mathrm{O}_{3}$ is large enough to totally reflect UCN trapped in a stainless steel bottle.

We have measured the effect of surface reflections by measuring the $\mathrm{UCN}$ absorption rate on a set of $1 \mathrm{~cm}$ diameter vanadium foils mounted on the wall of a $10 \mathrm{~cm}$ diameter $2 \mathrm{~m}$ long vertically mounted stainless steel guide in $10 \mathrm{~cm}$ steps at different elevations above beam height and comparing this to capture on hydrogen in set of $1 \mathrm{~cm}$ diameter polyethylene foils mounted at the same elevations. Polyethylene was assumed not to have surface effects. The $2.2 \mathrm{MeV}$ capture gamma ray was measured for the polyethylene targets and the $1.48 \mathrm{MeV}$ decay gamma ray from ${ }^{52} \mathrm{~V}$ was measured from the vanadium target. The data are shown in Figure 16. We have assigned a $100 \%$ error bar to each of these corrections to account for uncertainties in the assumptions about UCN interactions with the polyethylene surface.

The deficit observed in vanadium relative to n-p capture was fitted with a function that assumed it was due to a cut off at low velocity due to reflection from the oxide layer. Although this model is too simple to capture all of the physics it gives a good description of the data and gave a correction factor of 1.16(16). Applying these corrections gives a measured density of 52(9) UCN/ $\mathrm{cm}^{3}$ from the source when it is optimized, in fair agreement with the indirect estimate given above.

\section{CONCLUSIONS}

The Los Alamos spallation-driven UCN source has been commissioned. We have described a set of measurements and simulations that together give confidence that the source is performing as expected. Good agreement has 
been obtained between measurements and predictions based on MCNP5/MCNPX simulations and our Monte Carlo code which simulates UCN transport. Measurements of the cold neutron production, UCN production rate in the solid deuterium, and transport give results consistent with the measured UCN densities.

We conclude that with the average proton beam current of $5.8 \mu \mathrm{A}$, the UCN densities available for experiments of 52(9) $\mathrm{UCN} / \mathrm{cm}^{3}$ are competitive with densities which can be provided by sources at research reactors. The polarized density of $>2 \mathrm{UCN} / \mathrm{cm} 3$ provided to the UCNA experiment allowed this experiment to compete with cold neutron beam measurements of the neutron decay correlation parameter A. ${ }^{16}$

${ }^{1}$ R. Golub, D. Richardson, and S. K. Lamoreaux, Ultra-Cold Neutrons (American Institute of Physics, New York, 1991).

${ }^{2}$ V. K. Ignatovich, The Physics of Ultracold Neutrons (Clarendon, Oxford, 1990).

${ }^{3}$ S. K. Lamoreaux and R. Golub, J. Phys. G 36(10), 104002 (2009).

${ }^{4}$ J. Byrne, J. Morse, K. F. Smith, F. Shaikh et al., Phys. Lett. B 92(3-4), 274-278 (1980).

${ }^{5}$ M. Dewey, K. Coakley, D. Gilliam, G. Greene et al., Nucl. Instrum. Methods Phys. Res. A 611(2-3), 189-192 (2009).

${ }^{6}$ M. S. Dewey, D. M. Gilliam, J. S. Nico, F. E. Wietfeldt et al., Phys. Rev. Lett. 91(15), 152302 (2003)

${ }^{7}$ J. Last, M. Arnold, J. Doehner, D. Dubbers et al., Phys. Rev. Lett. 60(11), 995-998 (1988).

${ }^{8}$ W. Mampe, P. Ageron, C. Bates, J. M. Pendlebury et al., Phys. Rev. Lett. 63(6), 593-596 (1989)

${ }^{9}$ A. Pichlmaier, J. Butterworth, P. Geltenbort, H. Nagel et al., Nucl. Instrum. Methods Phys. Res. A 440(3), 517-521 (2000).

${ }^{10}$ A. Pichlmaier, V. Varlamov, K. Schreckenbach, and P. Geltenbort, Phys. Lett. B 693(3), 221-226 (2010).

${ }^{11}$ A. P. Serebrov, Phys.-Usp. 48(9), 867-885 (2005).

${ }^{12}$ A. P. Serebrov and A. K. Fomin, Phys. Rev. C 82(3), 035501 (2010).

${ }^{13}$ B. Yerozolimsky, A. Steyerl, O. Kwon, V. Luschikov et al., paper presented at the Neutron Spectroscopy, Nuclear Structure, Related Topics. XII International Seminar on Interaction of Neutrons with Nuclei, Dubna, Russia, 2005 (unpublished).

${ }^{14}$ R. E. Hill, J. M. Anaya, T. J. Bowles, G. L. Greene et al., paper presented at the International Workshop on Particle Physics with Slow Neutrons Inst Laue Langevin, Grenoble, France, 2000 (unpublished).

${ }^{15}$ K. Kirch, T. J. Bowles, B. Fillipone, P. Geltenbort et al., paper presented at the Application of Accelerators in Research and Industry. Sixteenth International Conference Denton, TX, 2000 (unpublished).

${ }^{16}$ J. Liu, M. P. Mendenhall, A. T. Holley, H. O. Back et al., Phys. Rev. Lett. 105(18), 181803 (2010).

${ }^{17}$ R. W. Pattie, Jr., H. O. Back, A. R. Young, and D. N. C. Triangle Universities Nuclear Laboratory et al., Phys. Rev. Lett. 102(1), 012301 (2009).
${ }^{18}$ R. Golub and K. Boning, Z. Phys. B 51(2), 95-98 (1983).

${ }^{19}$ Z. C. Yu, S. Malik, and R. Golub, Z. Phys. B 62(2), 137-142 (1986).

${ }^{20}$ Y. N. Pokotilovski, Nucl. Instrum. Methods Phys. Res. A 356(2-3), 412-414 (1995).

${ }^{21}$ A. Serebrov, V. Mityukhlyaev, A. Zakharov, M. Sazhin et al., paper presented at the Fifth Cryogenics '98 Iir International Conference Proceedings, Paris, France, 1998 (unpublished).

${ }^{22}$ A. P. Serebrov, paper presented at the International Workshop on Particle Physics with Slow Neutrons Inst Laue Langevin, Grenoble, France, 2000 unpublished).

${ }^{23}$ A. P. Serebrov, V. A. Mityukhlyaev, A. A. Zakharov, T. Bowles et al., JETP Lett. 66(12), 802-808 (1997).

${ }^{24}$ A. Anghel, F. Atchison, B. Blau, B. van den Brandt et al., Nucl. Instrum. Methods Phys. Res. A 611(2-3), 272-275 (2009).

${ }^{25}$ Y. Masuda, "Ultra cold neutron production with medium energy proton accelerator," Report No. 981-238-125-2 (World Scientific, Singapore, 2002).

${ }^{26}$ E. Korobkina, B. Wehring, A. Hawari, A. Young et al., Nucl. Instrum. Methods Phys. Res. A 579(1), 530-533 (2007).

${ }^{27}$ A. Frei, Y. Sobolev, I. Altarev, K. Eberhardt et al., Eur. Phys. J. A 34(2), 119-127 (2007).

${ }^{28}$ A. Frei, I. Altarev, E. Gutsmiedl, F. J. Hartmann et al., Verh. Dtsch. Phys. Ges. 43(3), 1 (2008).

${ }^{29}$ Y. Masuda, K. Hatanaka, S. C. Jeong, S. Kawasaki et al., Phys. Rev. Lett. 108(13), 134801 (2012).

${ }^{30}$ C. L. Morris, J. M. Anaya, T. J. Bowles, B. W. Filippone et al., Phys. Rev. Lett. 89(27), 272501 (2002).

${ }^{31}$ C. Y. Liu, A. R. Young, and S. K. Lamoreaux, Phys. Rev. B 62(6), R3581R3583 (2000).

${ }^{32}$ A. Saunders, J. M. Anaya, T. J. Bowles, B. W. Filippone et al., Phys. Lett. B 593, 55-60 (2004).

${ }^{33}$ F. Atchison, B. Blau, K. Bodek, B. van den Brandt et al., Nucl. Instrum. Methods Phys. Res. A 611, 252-255 (2009).

${ }^{34}$ C. M. Lavelle, C. Y. Liu, W. Fox, G. Manus et al., Phys. Rev. C 82(1), 015502 (2010).

${ }^{35}$ R. E. Hill, personal communication (2004).

${ }^{36}$ RCPC Monte Carlo N-Particle Transport Code System Including MCNP5 1.51 and MCNPX 2.6.0 and Data Libraries, 2008.

${ }^{37}$ MCNPX User's Manual, Version 2.6.0, edited by D. B. Pelowitz, Los Alamos National Laboratory, Report No. LA-CP-07-1473, 2008.

${ }^{38} \mathrm{X}-5$-Monte-Carlo-Team, MCNP-a General Monte Carlo N-Particle Transport Code, Version 5, Los Alamos National Laboratory, Report No. LAUR-03-198, 2003.

${ }^{39}$ Bergoz Instrumentation, see http://www.bergoz.com/index.php?option= com_content\&view=frontpage\&Itemid=1.

${ }^{40}$ U. Collaboration, B. Plaster, R. Rios, H. Back et al., preprint arXiv:1207.5887 (2012).

${ }^{41}$ Y. Xu, Ph.D. thesis, North Carolina State University, 2006.

${ }^{42}$ F. Atchison, B. Blau, K. Bodek, B. Van Den Brandt et al., Phys. Rev. Lett. 99(26), 262502 (2007).

${ }^{43}$ C. L. Morris, T. J. Bowles, J. Gonzales, R. Hill et al., Nucl. Instrum. Methods Phys. Res. A 599, 248-250 (2009).

${ }^{44}$ I. F. Silvera, Rev. Mod. Phys. 52(2), 393-452 (1980).

${ }^{45}$ C. Y. Liu, S. K. Lamoreaux, A. Saunders, D. Smith et al., Nucl. Instrum. Methods Phys. Res. A 508(3), 257-267 (2003). 